\title{
Ultrasound in abdominal trauma: an alternative to peritoneal lavage
}

\author{
J. A. CHAMBERS \& W. J. PILBROW \\ Accident Unit, Countess of Chester Hospital, Chester, England
}

\section{SUMMARY}

Ultrasonography has been used as an investigation in patients with abdominal signs after blunt injurý. Thirty-two patients were examined, of whom 11 had abnormal ${ }_{\text {? }}^{P}$ findings. Free intraperitoneal fluid was demonstrated in eight cases, seven of whom hadz this confirmed at subsequent laparotomy. The 21 patients with normal scans did not require abdominal intervention.

It is suggested that ultrasonography is a reliable method of detecting haemoperitg- $\vec{\circ}$ neum and offers a valuable non-invasive method of investigating blunt abdomingl injuries. The hepatorenal pouch is the site where free intraperitoneal fluid can be mogtt easily demonstrated.

\section{INTRODUCTION}

Ultrasonography has been available for many years and, during this time, equipment has become more compact and the quality of definition improved. The investigation has not, however, found an established role in the management of abdominal trauma.

Reports of false negative scanning of both liver and spleen have led to the conclusion that other modalities such as isotope scintigraphy and computerized tomography are 9 more reliable at assessing these organs (Kaufman et al., 1984; Froelich et al., 1982).

More recent articles have shown ultrasonography to be useful in investigation of children following trauma (Chambers et al., 1986; Booth et al., 1987). These paperso have emphasized the ability of ultrasound to demonstrate free intraperitoneal fluid and thus suggest visceral injury.

In 1970, Goldberg et al. reported the ability of ultrasound to detect $100 \mathrm{ml}$ of free intraperitoneal fluid.

The authors have used ultrasonography in the acute phase after injury primarily to

Correspondence: Mr F. A. Chambers, Registrar in Accident and Emergency, Countess of Chester Hospital, 0 Liverpool Road, Chester CH2 1BQ, England 
look for free fluid and as an alternative to peritoneal lavage. This paper reports their findings.

\section{MATERIALS AND METHODS}

The Accident Unit of the Countess of Chester Hospital, Chester, England, treats 48,000 new patients annually. In a 2-year period between September 1985 and September 1987 ultrasonography was used in an investigation in patients with suspected intra-abdominal injury on clinical examination.

Thirty-two patients were examined aged from 2-74 years. The procedure was usually performed in the ultrasound department adjacent to the Accident Unit. In some cases, the apparatus was brought to the patient's bedside in the resuscitation room.

Ultrasonography was performed by either a consultant radiologist or a senior registrar experienced in the technique. A G.L. scanner with a 3.5 and 5.0 $\mathrm{MHz}$ sector scanning probes was used. The patient remained in the supine position and views were taken via transabdominal and intercostal routes. Accident Unit medical and nursing staff were present during the procedure and, on occasions, the patient's relatives or parents.

\section{RESULTS}

Table 1 gives the results in those patients who were scanned. None of the 21 patients with normal scans required laparotomy. One of these patients, a 74-year-old man who had been involved in a road traffic accident, died shortly after admission. Post-mortem examination revealed extensive intrathoracic and limb injuries. No intra-abdominal bleeding was found.

Figure 1 demonstrates a normal scan of the hepato-renal pouch area and shows the direct contact between the liver and kidney at this site.

Table 2 gives details of those patients who had a positive scan. The three patients with renal injury all had visible perinephric haematomas. They settled with conservative management. Figure 2 demonstrates the free fluid in the hepato-renal pounch of a patient who underwent subsequent laparatomy and splenectomy.

Table 3 gives the details of management in those patients who had free fluid detected. In seven cases, after initial resuscitation and observation, a laparotomy was performed. All patients made a satisfactory recovery. It is of note that, despite examination of the

Table 1 Results of emergency abdominal ultrasound examinations

\begin{tabular}{ccc}
\hline Total no. of scans & Scan positive & Scan negative \\
\hline 32 & 11 & 21 \\
\hline
\end{tabular}




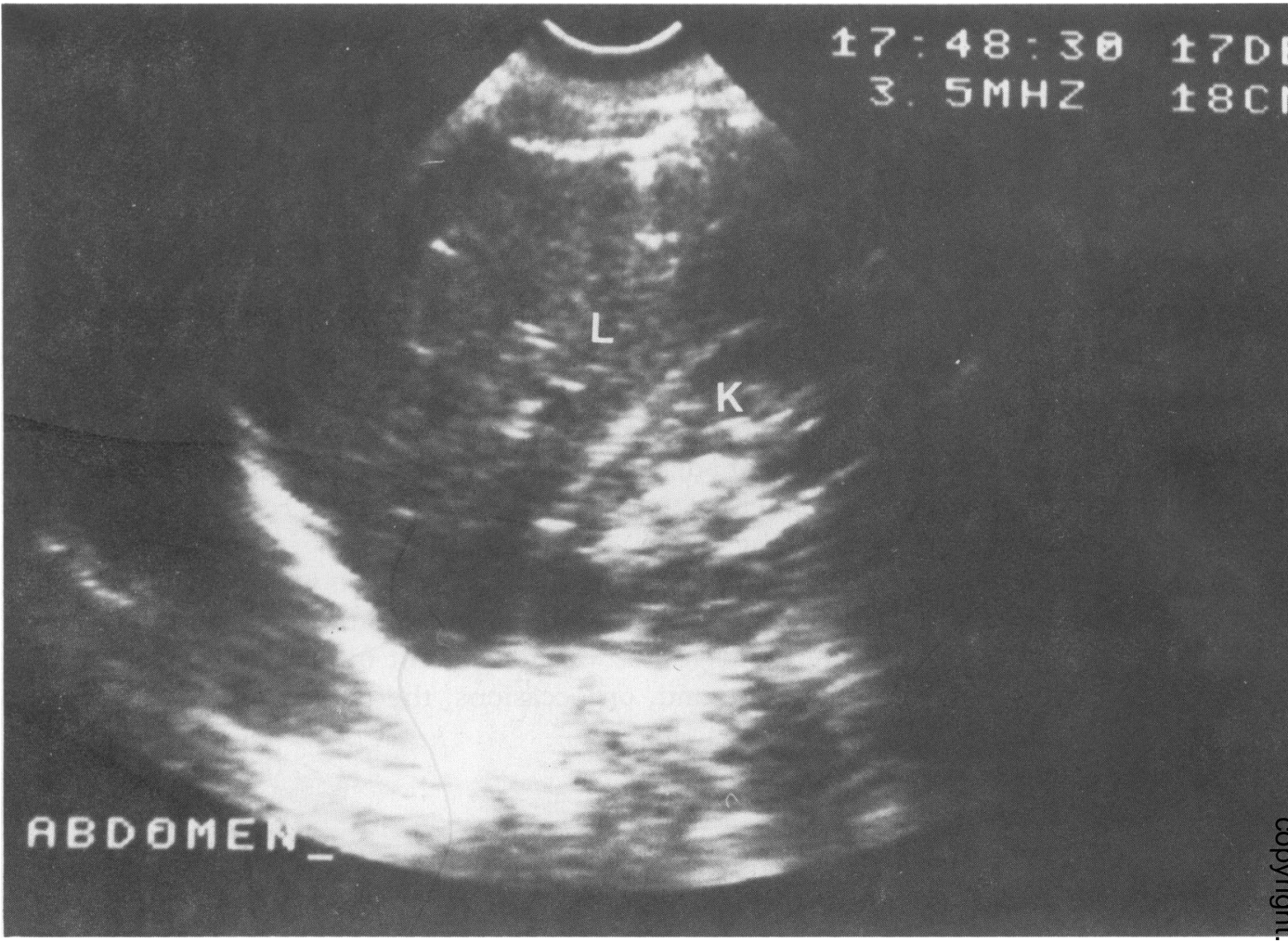

Fig. 1. Scan of the Hepato-renal pouch showing the area of contact between the liver $(L)$ and the right kidney (K).

splenic area and liver, in only one case was injury to these organs displayed (an intrasplenic haematoma). Figure 3 shows a large amount of free fluid in the pelvis of a young lady who subsequently was found to have a splenic injury.

In one case, a 30-year-old man who had been crushed in a machine at work, a small $\stackrel{3}{-\frac{3}{5}}$. amount of free fluid was detected in the subhepatic space. A conservative policy was 3 . adopted and, although he required analgesia for some days and developed paralytic $\delta$ ileus, he remained haemodynamically stable and made a full recovery.

During the period studied, two patients with suspected intraperitoneal bleeding 의 presented on an occasion when no radiologist was available. Peritoneal lavage was $\frac{D}{0}$ performed which was strongly positive. Both patients required laparotomy and splenectomy.

Table 2 Details of abnormality detected on scanning

\begin{tabular}{|c|c|c|}
\hline Total no. of positive scans & Free fluid & Renal injury \\
\hline 11 & 8 & 3 \\
\hline
\end{tabular}




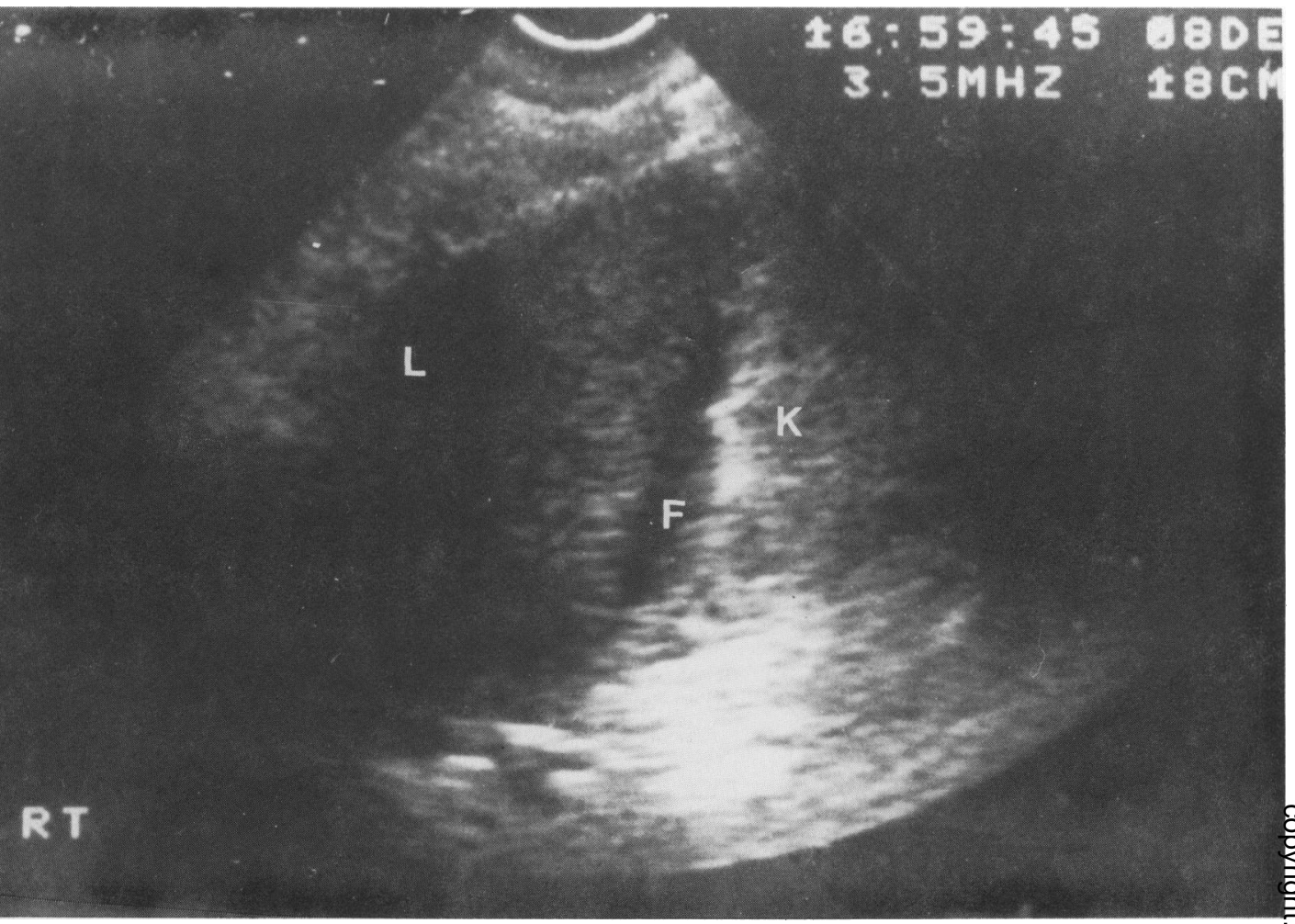

Fig. 2. Scan showing the liver (L) and kidney (K) separated by free intraperitoneal fluid (F).

\section{DISCUSSION}

The most commonly used investigative technique to aid the clinician in the assessment of abdominal trauma is peritoneal lavage. The technique only rarely yields a false positive result and a number of series have shown an absence of false negatives (van Dongen et al., 1985; Pachter \& Hofstetter, 1981). Peritoneal lavage is, however, invasive and reported complications include tearing of the small bowel mesentery (Soderstrom $e t$ al., 1980). The more formal 'open' technique of lavage has been described and shown to reduce both false positive results and complications (Pachter $\&$ Hofstetter, 1981). This procedure involves more extensive infraumbilical dissection under local anaesthetic.

Emergency minilaparoscopy has been reported as a useful technique by Berci $e t$ al. (1983). The investigation is performed under local anaesthetic using special apparatus. Intravenous sedation is sometimes required to improve tolerance.

In an effort to reduce the number of negative laparotomies following trauma, Asher $e t$ al. (1976) used ultrasonography to examine the splenic area in patients with weakly positive peritoneal lavage. Seventy patients were studied. The series produced 61 true negative cases, one false negative case, four true positives and four false positives. 
Table 3 Details of management of patients with detectable free fluid

\begin{tabular}{|c|c|c|}
\hline Management & Number of cases & \\
\hline Splenectomy & 5 & \\
\hline Splenectomy and repair of diaphragm & 1 & \\
\hline Repair hepatic laceration & 1 & \\
\hline Conservative & 1 & \\
\hline
\end{tabular}

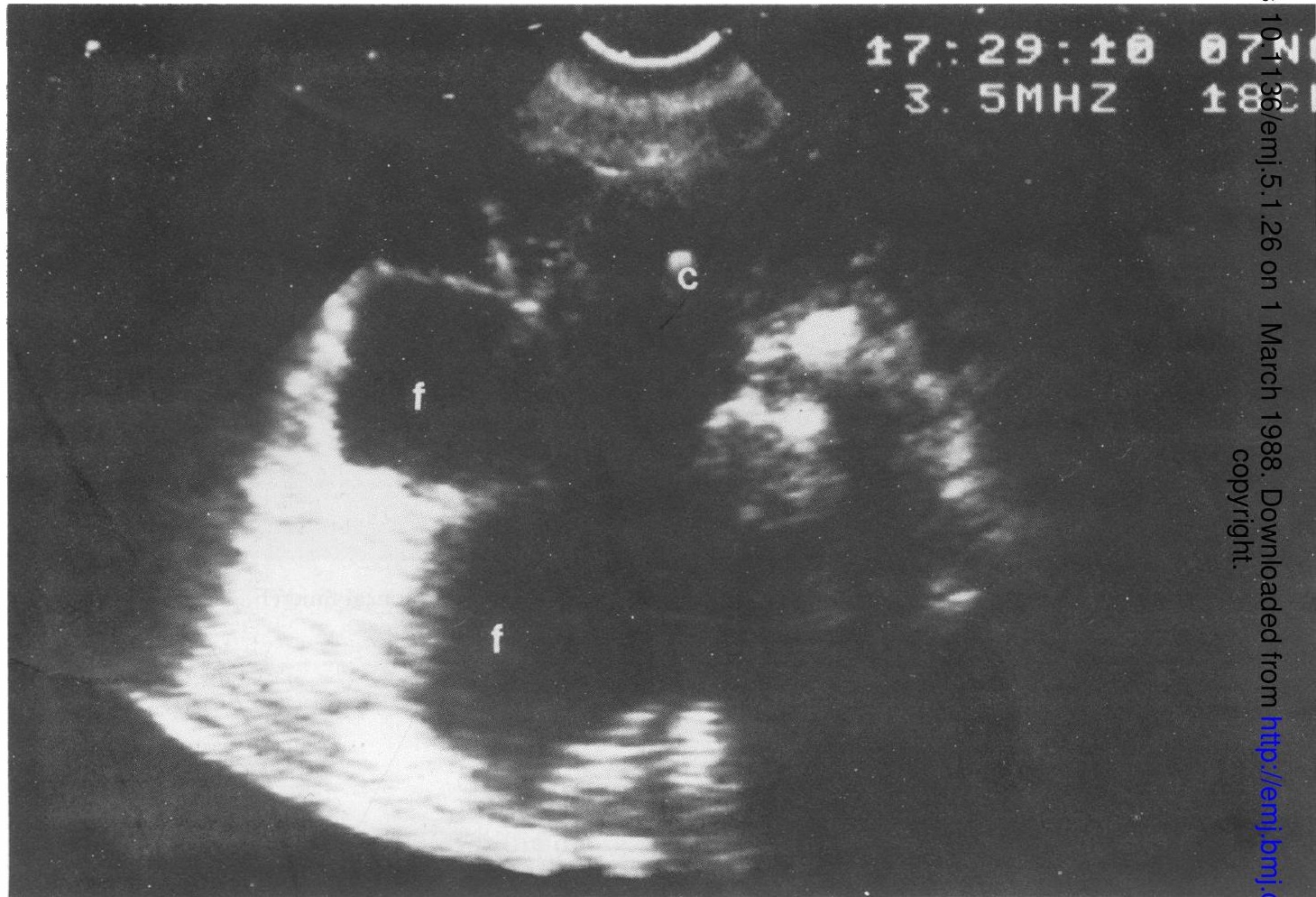

Fig. 3. Pelvic ultrasound scan demonstrating large amoints of free intraperitoneal fluid (FF). The bladder is empty and an intrauterine device (C) is in situ.

Ultrasound was recommended as a useful technique. The pre-selection of cases by earlier peritoneal lavage reduced the value of this study. Patients with strongly positive lavage were not investigated.

Foley \& Teele (1979) reported four cases of retroperitoneal injury in the epigastriumw shown by ultrasound. The scan prints illustrated in this paper are of low resolution and₹ clearly required great expertise in interpretation. Kay et al. (1980) used ultrasonography in the assessment of renal trauma. Seven patients were presented where the suggested abnormality on ultrasound scanning was confirmed subsequently. Ultrasono- 0 graphy was recommended as an adjunct to intravenous urograpy. 
When compared with other non-surgical methods of investigation in trauma, ultrasound scanning has proved to be less accurate. Kaufman et al. (1984) used the technique of ultrasound, isotope scintigraphy and computerized tomography in children. Twelve out of 24 patients with splenic injury on C.T. scanning had a normal ultrasound examination. Four out of 19 cases had liver damage shown by other modalities but not by ultrasonography. It is of note that only four out of 95 patients investigated in this series required operative treatment.

Froelich et al. (1982) compared isotope scintigraphy and ultrasonography in the detection of splenic trauma in a prospective study of 32 patients. Two patients were found to have a falsely normal ultrasound scan. They also stated that a proper examination of the splenic area had not been possible in six patients (19\%) due to poor cooperation or local factors such as an adjacent chest drainage tube.

A prospective multicentre diagnostic study of splenic injury has recently been reported from Norway (Wiig et al. 1987). Fifty-one patients with splenic injury seen on scintigraphy and/or computerized tomography were examined using ultrasound. Only 17 were said to have a 'positive' ultrasound and a further 26 an 'equivocal' ultrasound. In eight cases, the ultrasound scan was falsely normal. This trial concluded that ultrasonography was less reliable than the other techniques. Computerized tomography was recommended as the investigation of first choice. Scintigraphy suffered the major disadvantage of only being available during daytime hours.

Computerized tomography has been used as an investigation for many years in San Francisco. A recent series (Federle et al., 1987) reported 55 cases of splenic injury, confirmed surgically, in patients studied by tomography. One investigation was falsely negative. The most commonly detected abnormality was haemoperitoneum (98\%) followed by perisplenic haematoma $(85 \%)$ and splenic laceration $(71 \%)$. During the 6 years of this study, a total of 1500 patients had undergone tomography following blunt trauma. The diagnostic yield of significant splenic injury would seem extremely low considering the expense of equipment used and expertise required. It is of note that a total of 210 splenectomies had been performed following blunt trauma during the period evaluated. Clearly, the clinical decision to perform laparotomy was more commonly made without recourse to tomography.

A paper from Toronto (Pagliarello et al., 1987) has compared C.T. scanning with open peritoneal lavage in the identification of intraperitoneal injury. Fifteen patients were examined using both techniques (Tomography first) and a further 15 using tomography only. These were one false positive and three false negative examinations using tomography. Three falsely positive lavages were performed but no false negatives. The importance of meticulous technique, including the use of both intravenous and intragastric contrast material, is stressed by authors from Toronto and San Francisco if tomography is to be reliable. The Toronto group conclude that open peritoneal lavage remains the diagnostic modality of choice.

In the immediate period after injury, the clinician wants to know whether intraperitoneal bleeding is present or not. Blunt injury usually causes damage to parenchymatous organs or bowel mesentery. Bowel perforation is uncommon. Ultrasound scanning has the ability to detect free intraperitoneal fluid which, in practice, implies haemoperitoneum.

Booth et al. (1987) reported three cases in which the finding of free peritoneal fluid 
was the only initial abnormality. Later investigation using ultrasound and isotope $\mathrm{P}_{\mathrm{B}}^{\mathrm{B}}$ scintigraphy confirmed splenic injury. Chambers et al. (1986) found free peritoneal $\vec{\rho}$ fluid in four out of 15 children examined. Two of these children settled with 3 conservative management and were shown to have splenic injury on isotope scintigra $-\stackrel{?}{=}$ phy. The other two children underwent laparotomy and nephrectomy for severelyo disrupted kidneys.

The present authors have used ultrasonography as an initial investigation following $\frac{\bar{c}}{\bar{c}}$. blunt trauma in patients of all ages during a 2 -year period. They have found the technique to be a reliable means of detecting free intraperitoneal fluid. In seven out of eight cases, their positive finding has been confirmed surgically. None of the cases considered negative required surgical intervention. All examinations were well tolerated by the patient.

The authors' experience would confirm that ultrasonography does not give reliable information regarding significant injury to either liver or spleen. In only one case was $\stackrel{\nexists}{\exists}$ splenic injury definitely suspected on ultrasound.

In the recumbent patient, free intraperitoneal fluid will collect in the hepato-renali pouch (of Morison) and the pelvis. The pelvis may be difficult to examine witho ultrasound due to the presence of gas-filled loops of bowel. The hepato-renal pouch is apotential space not normally occupied by gas filled bowel. The ability to scan between $\frac{3}{20}$ the ribs allows good visualization of this area.

The authors suggest that ultrasound scanning of the hepato-renal pouch will reliably $\overrightarrow{0}$ reveal the presence or otherwise of free intraperitoneal fluid. In their practices, $\infty$ ultrasound examination has developed an established role as a non-invasive alternatioge to peritoneal lavage.

\section{ACKNOWLEDGEMENTS}

The authors wish to thank Dr J. E. Houghton and Dr. R. A. Sloka who performed some of the examinations in the series. They are also grateful to $\mathrm{Mr} \mathrm{J}$. Coals, Consultant in the Accident and Emergency Department, for allowing his patients to be examined.

\section{REFERENCES}

Asher W. M., Parvin S. \& Virgilio R. W. (1976) Echographic evaluation of splenic injury after blunt trauma.

Berci G., Dunkelman D., Michel S. C., Sandergs G., Wahlstrom E. \& Morgenstern L. (1983) EmergencyN minilaparoscopy in abdominal trauma. American fournal of Surgery 146, 261-5.

Booth A. J., Bruce D. I. \& Steiner G. M. (1987) Ultrasound diagnosis of splenic injury in children-the importance of free intraperitoneal fluid. Clinical Radiology 38, 395-8.

Chambers J. A., Ratcliffe J. F. \& Doig C. M. (1986) Ultrasound in abdominal injury in children. Injury 17, 399-403.

Federle M. P., Griffiths B., Minagi H. \& Jeffrey R. B. (1987) Splenic trauma: evaluation with C.T. radiology $162,69-71$ 
Foley L. C. \& Teele R. L. (1979) Ultrasound of epigastric injuries after blunt trauma. American fournal of Roentgenology 132, 593-8.

Froelich J. W., Simeone J. F., McKusick K. A., Winzelberg C. G. \& Strauss H. W. (1982) Radionuclide imaging and ultrasound in liver/spleen trauma: a prospective comparison. Radiology 145, 457-61.

Goldberg B. B., Goodman G. A. \& Clearfield H. R. (1970) Evaluation of ascites by ultrasound. Radiology 96, $15-22$.

Kaufman R. A., Towbin R., Babcock D. J., Gelford M. J., Guice K. S., Oldham K. T. \& Noseworthy J. (1984) Upper abdominal trauma in children: imaging evaluation. American fournal of Roentgenology 142, 449-60.

Kay C. J., Rosenfield A. T. \& Armm M. (1980) Gray-scale ultrasonography in the evaluation of renal trauma. Radiology 134, 461-6.

Pachter H. L. \& Hofstetter S. R. (1981) Open and percutaneous paracentesis and lavage for abdominal trauma. Archives of Surgery 116, 318-9.

Pagliarello G., Hanna S. S., Gregory W. D., McKee J. D., Harrison A. W., Taylor G. A., Miller H. A. B. \& Maggisano R. (1987) Abdominopelvic computerised tomography and open peritoneal lavage in patients with blunt abdominal trauma: a prospective study. Canadian fournal of Surgery 30, 10-13.

Soderstrom C. A., Du Prient R. W. \& Cowley R. A. (1980) Pitfalls of peritoneal lavage in blunt abdominal trauma. Surgery, Gynaecology and Obstetrics 151, 513-8.

van Dongen L. M. \& de Boer H. H. M. (1985) Peritoneal lavage in closed abdominal injury. Injury 16, $227-9$.

Wiig J. N., Solheim K., Nygaard K., Anda O., Runden T., Halvorsen J. F., Andenaes K., Dahl S., Danielsen S., Giercksky K.-E., Granlund O. G., Gruner O. P., Haugstvedt T. K., Lien E., Loe B., Lotveit T., Naess A. \& Strand K. (1987) Splenic injury-a prospective multicentre diagnostic study. Injury 18, 89-92. 